\title{
Towards a secure basis for the design of geothermal piles
}

\author{
Thomas Mimouni $\cdot$ Lyesse Laloui
}

Received: 28 August 2012/Accepted: 28 March 2013/Published online: 12 May 2013

(C) Springer-Verlag Berlin Heidelberg 2013

\begin{abstract}
Using pile foundations as heat exchangers with the ground provides an efficient and reliable energy source for the heating and cooling of buildings. However, thermal expansion or contraction of the concrete brings new challenges to the design of such structures. The present study investigates the impact of temperature variation on the mobilised bearing capacities of geothermal piles. The mechanisms driving the variations and redistribution of mobilised bearing forces along geothermal piles are identified using Thermo-Pile software. The EPFL and Lambeth College test piles are modelled and analysed as real-scale experiments. Three simple representative cases are used to investigate the impact of over-sizing geothermal piles on their serviceability. It is found that the mechanisms responsible for the variations and redistribution of mobilised bearing forces along the piles are unlikely to cause geotechnical failure, even if the ultimate bearing force of a pile is reached. Furthermore, over-sizing geothermal piles compared to conventional piles can have a negative impact on their serviceability.
\end{abstract}

Keywords Bearing capacity - Design - Geothermal pile · Load-transfer method $\cdot$ Stress $\cdot$ Strain

\section{Introduction}

Geothermal piles are pile foundations equipped with absorber pipes to allow heat exchange with the surrounding ground. However, thermal expansion or contraction of the concrete induces thermal strains and stresses that bring new challenges for the design of such structures $[4,11]$.

T. Mimouni · L. Laloui $(\varangle)$

Laboratory of Soil Mechanics, Ecole Polytechnique Fédérale de Lausanne, Station 18, 1015 Lausanne, Switzerland

e-mail: lyesse.laloui@epfl.ch
Thermal strains are the result of the equilibrium between the thermal stresses and mobilised bearing capacities, which depend on the pile confinement [10-12].

This paper gives insight into the processes driving the variations and redistribution of bearing capacities along geothermal piles under monotonic temperature variation. It also investigates the non-failing mechanisms-from a geotechnical standpoint-occurring in geothermal piles when they are heated or cooled.

This study is carried out using the Thermo-Pile software, based on the load-transfer method for both the mechanical and thermal loadings [9].

The first section presents the different case studies that were selected. Two full-scale in situ experiments, against which the software was validated [9], are used as examples of real applications. Three representative cases of floating, semifloating and end-bearing piles are also analysed and compared.

The second section presents the method employed to compute the bearing capacities and how they are split into different terms in order to explain the different mechanisms.

The third section presents the results of the analyses and identifies the mechanisms driving the variations and redistribution of mobilised bearing capacities.

Finally, the last section describes the non-failing character of the mechanisms identified in a single geothermal pile and discusses the impact of over-design on the pile serviceability.

\section{Case studies}

2.1 Real-scale in situ case studies

\subsubsection{The EPFL test pile}

A geothermal test pile was installed below a building on the campus of Ecole Polytechnique Fédérale de 
Lausanne (EPFL) in order to monitor the pile behavior under real service conditions. The pile is the only geothermal pile connected to its raft and is $25.8 \mathrm{~m}$ long and $0.88 \mathrm{~m}$ in diameter. The absorber pipes are connected in parallel through collectors at the inlet and outlet of the pile [11].

The Young's modulus of the concrete was estimated using sonic coring data [11] and was found to be around 29.2 GPa [9]. The thermal expansion of the concrete is taken equal to $10^{-5}{ }^{\circ} \mathrm{C}^{-1}[5,15]$. The pile is embedded in a layered soil made up of two thin alluvial layers at the top, a thick layer of moraine and the molasse bedrock at the base (Fig. 1). The different parameters used to model the soil layers were estimated by Knellwolf et al. [9] and are listed in Table 1. The interaction between the pile head and the overlying building is modelled as a linear spring whose stiffness $K_{\mathrm{h}}$ was estimated to be $2 \mathrm{GPa} / \mathrm{m}$ [9]. The mechanical load $P$ applied to the EPFL test pile at the end of the building construction was estimated as $1,000 \mathrm{kN}$ [9]. Based on the soil properties used for the study, the factor of safety (i.e. the ultimate bearing force of the pile divided by the load $P$ ) of the EPFL test pile is approximately 13. In fact, this test pile was deliberately over-designed in order to prevent any potential damage to the building caused by its heating and cooling.

\subsubsection{The Lambeth College test pile}

The Lambeth test pile was built away from any existing buildings. This test pile was $22.5 \mathrm{~m}$ long with an upper diameter of $0.61 \mathrm{~m}$ and a lower diameter of $0.55 \mathrm{~m}$

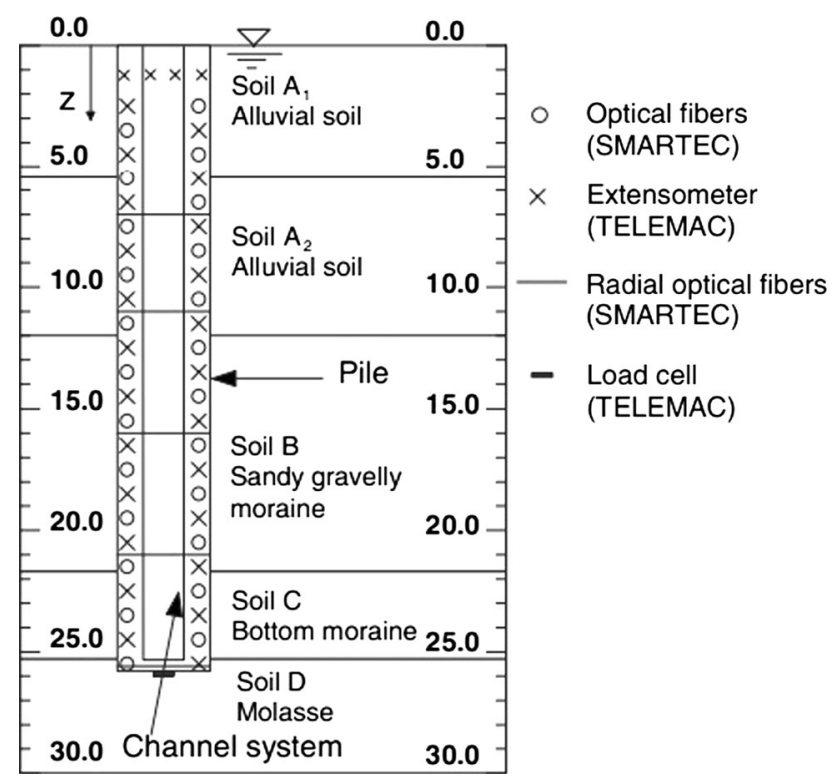

Fig. 1 Stratigraphy and instrumentation of the EPFL test pile from Laloui et al. [11]
Table 1 Soil parameters used to model the EPFL test pile, after Knellwolf et al. [9]

\begin{tabular}{llllll}
\hline Soil layer & A1 & A2 & B & C & D \\
\hline Depth $(\mathrm{m})$ & $0-5.5$ & $5.5-12$ & $12-22$ & $22-25$ & $25-25.8$ \\
$K_{\mathrm{s}}(\mathrm{MPa} / \mathrm{m})$ & 16.7 & 10.8 & 18.2 & 121.4 & - \\
$q_{\mathrm{s}}(\mathrm{kPa})$ & 102 & 70 & 74 & 160 & - \\
$K_{\mathrm{b}}(\mathrm{MPa} / \mathrm{m})$ & - & - & - & - & 667.7 \\
$q_{\mathrm{b}}(\mathrm{MPa})$ & - & - & - & - & 11 \\
\hline
\end{tabular}

(Fig. 2). Mechanical loading was achieved with a jack mounted on a beam linked to the anchor piles. The absorber pipes were deployed around the reinforcement cage of the pile; these were connected to a heat sink pile through a heat pump to allow effects of heating and cooling to be investigated [4].

The thermal expansion and Young's modulus of the pile were estimated to be $8.5 \times 10^{-6}{ }^{\circ} \mathrm{C}^{-1}$ and $40 \mathrm{GPa}$, respectively [4]. The stiffness representing the interaction between the pile head and the overlying structure was estimated to be $10 \mathrm{GPa} / \mathrm{m}$ during heating and $0.1 \mathrm{GPa} / \mathrm{m}$ while cooling [9].

Knellwolf et al. [9] obtained representative characteristics for the stratigraphy in which the Lambeth test pile was embedded. These values are listed in Table 2, and the first 6.5-m-thick layer was ignored from a design standpoint. With a pile load of $1,200 \mathrm{kN}$, the factor of safety of the test pile at the Lambeth College is 1.73 .

\subsection{Representative case studies}

Three representative cases outlined in the work of Knellwolf et al. [9] were slightly modified in order to quantify the sensitivity of the main groups of onshore compression piles to temperature changes. Floating piles transfer their load to the ground through shaft friction exclusively while end-bearing piles transmit their load to a stiff substratum mainly through base compression. Semi-floating piles represent an intermediate configuration where both shaft friction and pile tip compression play a significant role. The selected configuration remains simple in order to properly identify the mechanisms induced by the heating and cooling of the piles. Therefore, a single 10-m-long pile with a diameter of $0.5 \mathrm{~m}$ is investigated. It is embedded is embedded in a homogeneous layer of soil whose characteristics vary according to the pile type; these parameters are listed in Table 3. The ultimate shaft friction and base reaction are chosen so that the ultimate bearing forces have the same order of magnitude. The mechanical loads (P) applied to each pile were chosen so that the ultimate bearing force of the piles is equal to $2.5 P$ (i.e. the factor of safety for each pile is 2.5 ). Head stiffness was taken equal 


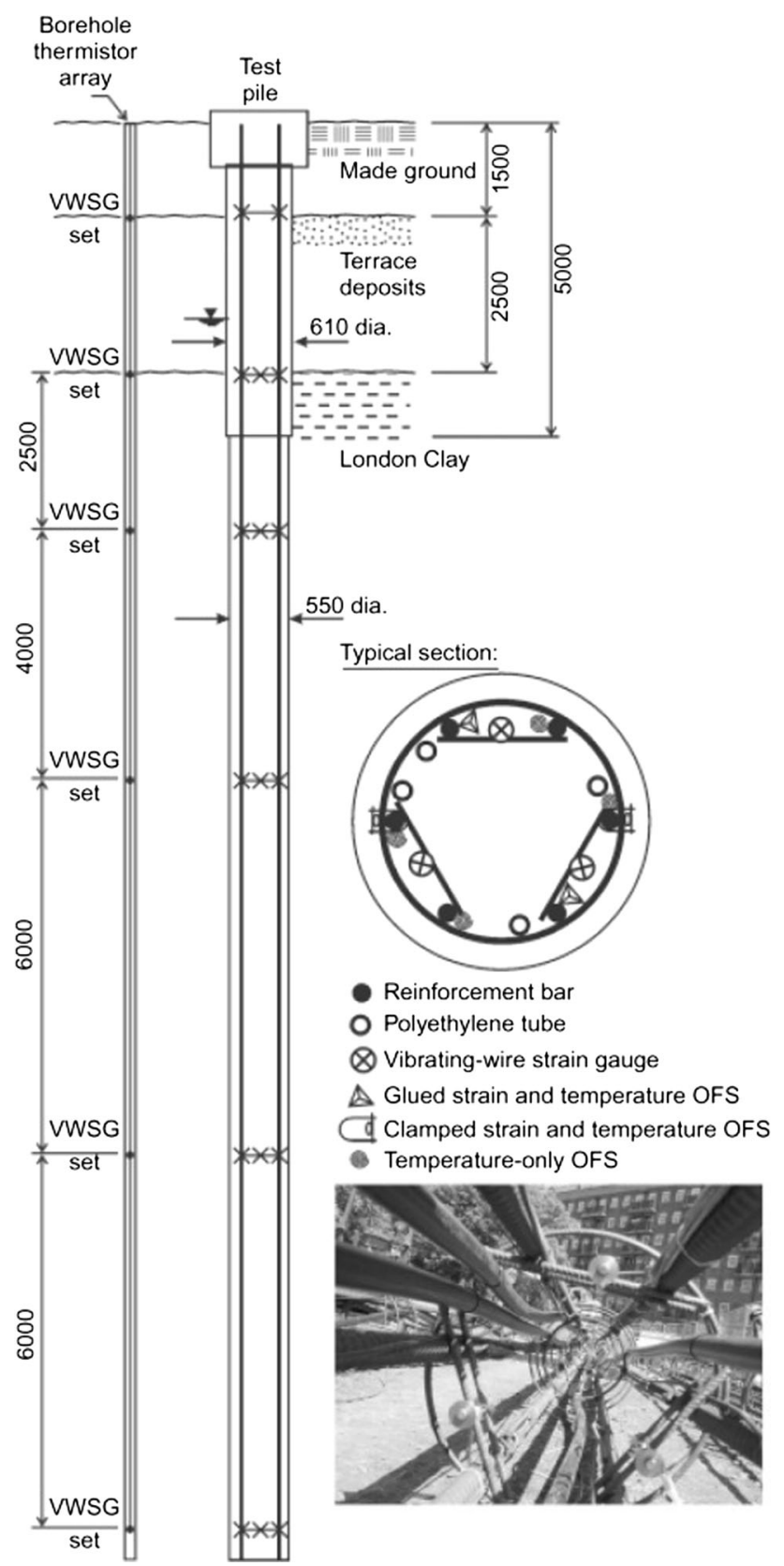

Fig. 2 Stratigraphy of the Lambeth test pile, after Bourne-Webb et al. [4]

Table 2 Soil parameters used to model the Lambeth test pile, after Knellwolf et al. [9]

\begin{tabular}{lllll}
\hline Soil layer & 1 & 2 & 3 & 4 \\
\hline Depth $(\mathrm{m})$ & $0-6.5$ & $6.5-10.5$ & $10.5-16.5$ & $16.5-22.5$ \\
$E_{\mathrm{M}}(\mathrm{MPa})$ & 0 & 45 & 45 & 45 \\
$q_{\mathrm{s}}(\mathrm{kPa})$ & 0 & 60 & 70 & 80 \\
$q_{\mathrm{b}}(\mathrm{kPa})$ & - & - & - & 460 \\
\hline
\end{tabular}

to $10 \mathrm{GPa} / \mathrm{m}$ for all cases. The Young's modulus and thermal expansion coefficient of the pile are taken to be equal to $30 \mathrm{GPa}$ and $10^{-5}{ }^{\circ} \mathrm{C}^{-1}$, respectively.

\section{Methods}

\subsection{Bearing capacities of axially loaded piles}

The bearing capacities of conventional axially loaded piles (for a load $P$ ) take two forms. The base reaction $Q_{\mathrm{b}}$ transfers part of the load through compression of the soil below the pile tip, while the shaft friction $Q_{\mathrm{s}}$ transfers a part of the load through shear stress at the pile-soil interface.

The mobilisation of bearing capacities can be modelled with the load-transfer approach [6, 14]. The pile-soil interaction system is represented by an elastoplastic model, which utilises the load-transfer curves that link the mobilised bearing forces to pile displacements [3, 7, 13]. The load-transfer curves employed in the present study were proposed by Frank and Zhao [8] and are defined using a plateau value $q$ and an initial slope $K$ (Fig. 3 ).

The ultimate shaft friction $q_{\mathrm{s}}$ and base reaction $q_{\mathrm{b}}$ represent the maximum resistance that a layer of soil can provide and those quantities can be estimated based on the soil properties [8].

The elastic branches $K_{\mathrm{s}}$ and $K_{\mathrm{b}}$ of the load-transfer curves can be estimated from the Menard pressuremeter modulus $E_{\mathrm{M}}$ in cohesive soils with $[1,8]$ :

$$
\begin{aligned}
K_{\mathrm{b}} & =\frac{11 E_{\mathrm{M}}}{D} \\
K_{\mathrm{s}} & =\frac{2 E_{\mathrm{M}}}{D}
\end{aligned}
$$

Examples of the load-transfer curves are given in Fig. 3. Shaft friction and base reaction are mobilised according to an elastic branch until they reach half of their ultimate values. Then, the slopes of the load-transfer curves change to a fifth of the elastic moduli. When shaft friction or base reaction reaches its ultimate value, the load-transfer curves follow a plateau equal to the ultimate resistance. For both bearing mechanisms, unloading is parallel to the elastic branch (Fig. 3).

Assuming that the pile cross section is circular and constant with depth, the mobilised bearing strengths through shaft friction $Q_{\mathrm{s}, \mathrm{mob}}$ and through base compression $Q_{\text {b,mob }}$ can be estimated using:

$$
\begin{aligned}
Q_{\mathrm{s}, \mathrm{mob}} & =\pi D \int_{0}^{L} t_{\mathrm{s}} \cdot \mathrm{d} z \\
Q_{\mathrm{b}, \mathrm{mob}} & =\frac{\pi D^{2}}{4} t_{\mathrm{b}},
\end{aligned}
$$


Table 3 Soil parameters, pile-structure stiffness and temperature variations considered for the floating pile, end-bearing pile and semifloating pile

\begin{tabular}{llll}
\hline Parameters & Floating pile & $\begin{array}{l}\text { Semi- } \\
\text { floating } \\
\text { pile }\end{array}$ & $\begin{array}{l}\text { End- } \\
\text { bearing } \\
\text { pile }\end{array}$ \\
\hline $\begin{array}{l}\text { Ultimate shaft friction } q_{\mathrm{s}} \\
(\mathrm{kPa})\end{array}$ & 100 & 100 & 0 \\
$\begin{array}{l}\text { Ultimate base reaction } q_{\mathrm{b}} \\
(\mathrm{MPa})\end{array}$ & 0 & 9 & 9 \\
$\begin{array}{l}\text { Mechanical load } P(\mathrm{kN}) \\
\text { Menard modulus } E_{\mathrm{M}}(\mathrm{MPa})\end{array}$ & 628 & 1,335 & 707 \\
$\begin{array}{l}\text { Head stiffness } K_{\mathrm{h}}(\mathrm{GPa} / \mathrm{m}) \\
\text { Temperature variation }\end{array}$ & 10 & 60 & 60 \\
$\Delta T\left({ }^{\circ} \mathrm{C}\right)$ & $-10-+60$ & $-10-+60$ & $-10-+60$ \\
\hline
\end{tabular}

where $t_{\mathrm{s}}$ represents the shaft friction mobilised at a depth $z$ along the pile shaft, $t_{\mathrm{b}}$ represents the compression at the pile tip, which is assumed to be constant across the pile base, and $L$ is the pile length. Similarly, the ultimate bearing capacities $Q_{\text {s,ult }}$ and $Q_{\text {b,ult }}$ can be computed from the ultimate shaft resistance and base compression with:

$$
\begin{aligned}
Q_{\mathrm{s}, \text { ult }} & =\pi D \int_{0}^{L} q_{\mathrm{s}} \cdot \mathrm{d} z \\
Q_{\mathrm{b}, \mathrm{ult}} & =\frac{\pi D^{2}}{4} q_{\mathrm{b}}
\end{aligned}
$$

In conclusion, this study uses the load-transfer approach proposed by Seed and Reese [14] and Coyle and Reese [6] to estimate the bearing capacities of piles under mechanical loading.

\subsection{Bearing capacities of a geothermal pile}

As a foreword to this section, the terms "redistribution" and "variation" of mobilised bearing capacities are discussed for a geothermal pile. Indeed, the term "redistribution" implies that no overall variation of the total mobilised bearing capacity was experienced. Conversely, the term "variation" implies a change (i.e. increase or decrease). The following paragraph discusses when redistribution and variation occur.

Let us consider two identical piles that are loaded with the same dead load $P$. Pile \#1 is below a raft, while pile \# 2 is not located below a structure. Obviously, pile \#1 is representative of real service conditions but the comparison with pile \#2 remains useful for understanding the analysed mechanisms.

When either pile is heated or cooled, it expands or contracts and local variations of the mobilised bearing capacities due to thermal displacements are observed. However, writing the static equilibrium for each pile after a temperature change yields:

$$
\begin{aligned}
& P+R_{1}=Q_{\text {th } 1} \\
& P=Q_{\text {th } 2}
\end{aligned}
$$

where $R_{1}$ is the reaction of the raft to the head heave of pile $\# 1$, and $Q_{\mathrm{th} 1}$ and $Q_{\mathrm{th} 2}$ are the mobilised bearing capacities under mechanical and thermal loadings for pile \#1 and pile \#2, respectively.

Obviously, pile \#1 and pile \#2 mobilised the same bearing capacities, equal to $P$, prior to any temperature variation since they were carrying the same dead load $P$. Nevertheless, once they experience a temperature variation, a redistribution of mobilised bearing capacity occurs in pile \#2 while a variation is observed in pile \#1. Indeed,
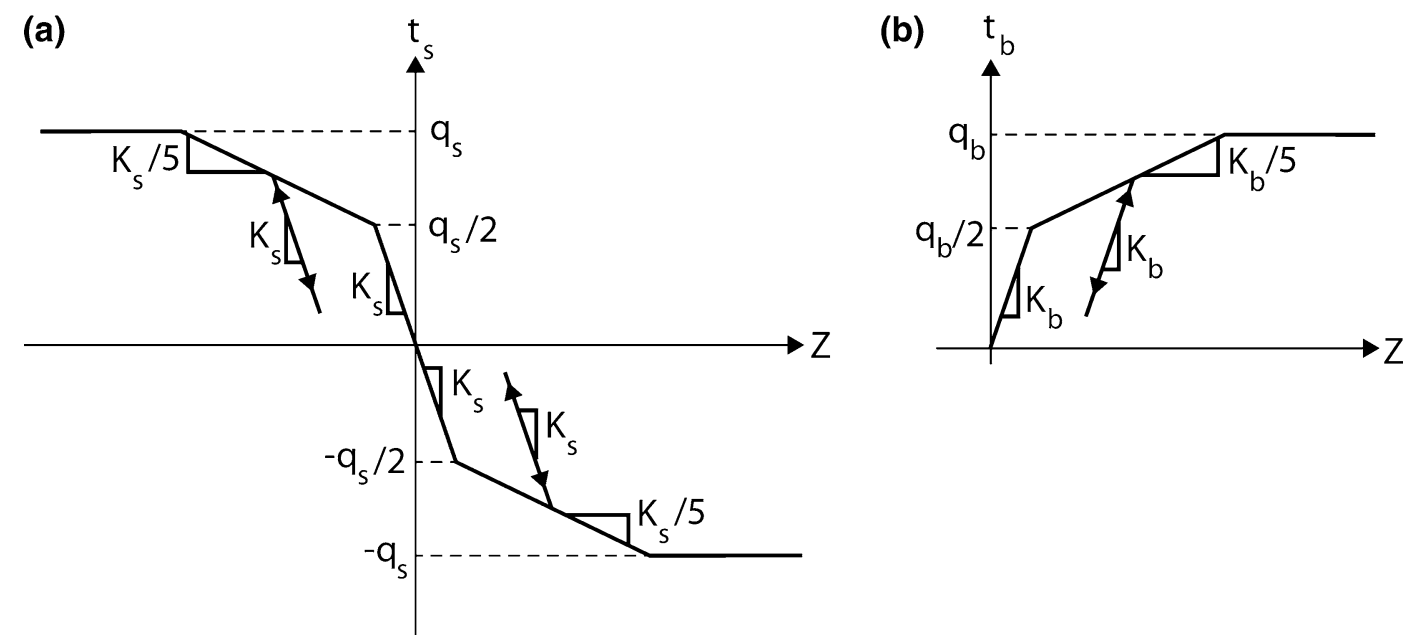

Fig. 3 Example of load-transfer curves used for shaft friction (a) and base compression (b); $z$ is the displacement, taken positive when upward 
since pile \#2 is only subjected to $P$ from the exterior, its static equilibrium implies that the mobilised bearing capacity remains equal to $P$. Conversely, the head heave of pile \#1 induces a new external force on the pile through the raft reaction $R_{1}$.

In conclusion, the mobilised bearing capacities of single geothermal piles are expected to vary with temperature.

In the present study, geothermal piles are represented as axially loaded piles undergoing axial thermal expansion or contraction under thermal loading. Their deformations occur around the null point, which does not move during temperature variation. Therefore, the portion of the pile above the null point experiences upward displacements, while the part below it experiences downward displacements during thermal expansion of the pile. Conversely, the section of the pile above the null point settles, while the part below it heaves when a pile is cooled (i.e. during thermal contraction) [4, 9].

Thus, the geothermal pile can be divided into two parts delineated by the null point. The part above the null point will be later called the "upper part of the pile", while the "lower part of the pile" will refer to the section below the null point.

As a result, the overall mobilised bearing force $Q_{\text {mob }}$ can be split into a portion $Q_{\text {mob,up }}$ acting on the upper part of the pile and a portion $Q_{\text {mob,low }}$ acting on the lower part of the pile. Similarly, the shaft friction can be divided into a portion acting on the upper part of the $\left(Q_{\mathrm{s}, \mathrm{mob}, \mathrm{up}}\right)$ and a portion acting on the lower part of the pile $\left(Q_{\mathrm{s}, \text { mob,low }}\right)$ [see Eq. (5)].

Furthermore, a capping force may develop under the reaction of the supported structure (raft, wall...) as the pile head heaves or settles. This action is combined with the mechanical load $\mathrm{P}$ into the head reaction $Q_{\mathrm{h}}$ in Eq. (7).

Thus, $Q_{\text {mob}}, Q_{\text {mob,up }}$ and $Q_{\text {mob,low }}$ can be expressed as follows:

$$
\begin{aligned}
& Q_{\text {mob }}=Q_{\text {mob,up }}+Q_{\text {mob,low }} \\
& Q_{\text {mob,up }}=Q_{\text {s,mob,up }} \\
& Q_{\text {mob,low }}=Q_{\text {b,mob }}+Q_{\text {s,mob,low }}
\end{aligned}
$$

Let $z_{\mathrm{NP}}$ be the depth of the null point and $L$ the pile length. The terms $Q_{\mathrm{s} \text {,mob,low }}$ and $Q_{\text {s,mob,up }}$ can then be computed from Eq. (2) as follows:

$$
\begin{gathered}
Q_{\text {s,mob,up }}=\pi D \int_{0}^{z_{\mathrm{NP}}} t_{\mathrm{s}} \cdot \mathrm{d} z \\
Q_{\mathrm{s}, \text { mob,low }}=\pi D \int_{z_{\mathrm{NP}}}^{L} t_{\mathrm{s}} \cdot \mathrm{d} z
\end{gathered}
$$

It is obvious that the null point definition does not hold when the temperature variation is zero. Therefore, the graphs presented in the following analyses will exhibit a discontinuity in 0 for the two friction terms given in Eq. (6), while the base and head reactions are defined for a zero temperature variation (i.e. under mechanical load only).

The head action $Q_{\mathrm{h}}$ includes the mechanical load $P$ and the raft capping reaction, which is modelled using a linear elastic relationship linking the head reaction to the head heave $z_{\mathrm{h}}$ and head stiffness $K_{\mathrm{h}}$ (in $\mathrm{Pa} / \mathrm{m}$ ):

$Q_{\mathrm{h}}=P+\frac{\pi D^{2}}{4} K_{\mathrm{h}} z_{\mathrm{h}}$

Thus, using the decomposition in Eq. (5), the mobilised bearing capacities will vary as follows when the pile is heated:

- The mobilised resistance at the head of the pile, $Q_{\mathrm{h}}$, increases because the pile head heaves.

- The mobilised shaft friction along the upper part of the pile, $Q_{\text {s,mob,up, decreases because axial displacements }}$ occur in the upward direction. Negative friction can develop depending on the magnitude of the displacements.

- The mobilised base resistance, $Q_{\mathrm{b}, \mathrm{mob}}$, increases because thermally induced axial displacements in the lower part of the pile occur in the downward direction. The ultimate base reaction may be reached depending on the magnitude of the displacements.

- The mobilised shaft friction along the lower part of the pile, $Q_{\text {s,mob,low }}$, increases because axial displacements occur in a downward direction. The ultimate shaft friction may be reached depending on the magnitude of the temperature increase.

Conversely, when the pile is cooled:

- The mobilised resistance at the head of the pile, $Q_{\mathrm{h}}$, decreases. The capping reaction of the raft occurs in the upward direction and pulls on the pile head as it settles.

- The mobilised shaft friction along the upper part of the pile, $Q_{\text {s,mob,up }}$, increases because the axial displacements occur in the downward direction.

- The mobilised base resistance, $Q_{\mathrm{b}, \mathrm{mob}}$, decreases because the pile tip heaves. If the pile tip heave is large enough that the contact between the pile base and the soil is broken (i.e. higher than the elastic unloading displacement at the pile base), the base reaction reaches zero.

- The mobilised shaft friction along the lower part of the pile, $Q_{\text {s,mob,low }}$, decreases because axial displacements occur in the upward direction.

The sign convention adopted in the analyses is as follows (Fig. 4):

- Upward shaft friction is taken as positive 


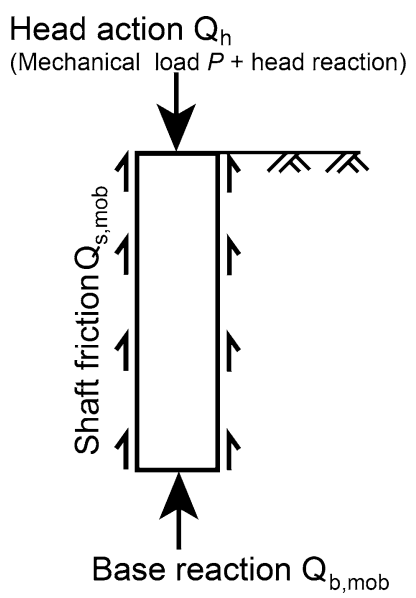

Fig. 4 Schematic of forces acting on a pile foundation

- A positive base reaction acts upwards

- The mechanical load $P$ is given as positive but acts downward

- Upward displacements are taken as positive

- $K_{\mathrm{h}}$ is a positive quantity so that the positive head reaction acts downward, in order to have the same sign convention as the mechanical load $P$

These conventions were used in order to obtain positive left- and right-hand sides in the pile equilibrium equation:

$P+\frac{\pi D^{2}}{4} K_{\mathrm{h}} \cdot z_{\mathrm{h}}=Q_{\mathrm{s}, \mathrm{mob}}+Q_{\mathrm{b}, \mathrm{mob}}$

In summary, the mobilised bearing capacities of geothermal piles are expected to vary with temperature and to be redistributed according to the position of the null point.

\subsection{Variations of shaft friction}

While the evolutions of the base reaction and head action are simple to estimate since they occur at single depths, the mobilisation of friction along the pile shaft is less straightforward.

To simplify the analysis, one can split the mobilised shaft friction into a static portion $Q_{\mathrm{s} \text {, mob,static }}$ (only due to the mechanical load $P$, prior to any temperature change) that is independent from the temperature and a portion $\Delta Q_{\mathrm{s}, \mathrm{mob}}$ that depends on temperature and depth as follows:

$Q_{\mathrm{s}, \text { mob }}(\Delta T, z)=Q_{\mathrm{s}, \text { mob, static }}(z)+\Delta Q_{\mathrm{s}, \text { mob }}(\Delta T, z)$

As described above, heating (cooling) the pile causes downward (upward) displacements in the lower part of the pile, while upward (downward) displacements occur in the upper part of the pile. By definition, the null point is the point where thermally induced displacement is zero and consequently where the shaft friction remains unchanged (i.e. $\left.\Delta Q_{\mathrm{s}, \mathrm{mob}}\left(\Delta T, z_{\mathrm{NP}}\right)=0\right)$.
As a result, thermally induced displacements always increase from the null point to the pile ends (i.e. head and tip). The shaft friction within an homogeneous layer of soil will vary depending on the location of this layer relative to the null point as follows:

- The greatest variation in shaft friction, $\Delta Q_{\mathrm{s}, \mathrm{mob}}$, within a layer of soil below the null point occurs at its base, while the smallest variation is located at the top of the soil layer. The friction increases with heating and decreases with cooling.

- The greatest variation in shaft friction within a layer of soil above the null point occurs at its top, while the smallest variation is located at the base of the layer. The friction decreases with heating and increases with cooling.

In summary, the shaft friction is divided into a mechanically mobilised portion, which remains constant over all temperatures, and a portion that varies with the temperature of the pile.

\section{Analyses}

\subsection{Full-scale in situ case studies}

The full-scale in situ test piles at EPFL and Lambeth College were utilised as real-case illustrations. Temperature variations in the piles were assumed to be between -10 and $+60{ }^{\circ} \mathrm{C}$ relative to $11^{\circ} \mathrm{C}$, the average natural ground temperature found at European latitudes. Therefore, the absolute temperature of the piles varies between +1 and $+70{ }^{\circ} \mathrm{C}$, the upper limit being representative of extreme solar thermal heat storage through geothermal foundations.

\subsubsection{Evolution of bearing capacities with temperature}

4.1.1.1 The EPFL test pile The semi-floating behaviour of the EPFL test pile is clearly seen in the distribution of bearing capacities with significant base compression and shaft friction. Heating of the pile results in increased head action, base reaction and mobilised shaft friction below the null point while the friction along the upper part of the pile decreases and can even become negative. Cooling the pile reduces the shaft friction in the lower part of the pile as well as the base reaction and head action, but increases the mobilised shaft friction above the null point (Fig. 5).

Changes in the slopes of the mobilised bearing capacities are observed at around $+20{ }^{\circ} \mathrm{C}$ (Fig. 5), when the null point moves upward (Fig. 14). Indeed, ascension of the null point along the pile axis enlarges the lower part of the pile, while it reduces the upper part of it. As a result, the part of the pile available to generate upward displacements through thermal expansion is shortened. Therefore, the 
head reaction does not vary linearly despite the fact that the head stiffness $K_{\mathrm{h}}$ is set as a constant.

Sharp variations in shaft friction occur along the pile close to a zero temperature variation (Fig. 5), mainly due to the large displacements of the null point with temperature in that narrow interval (Fig. 14). Furthermore, the null point is not defined for no temperature variation so it is not possible to differentiate the terms in Eq. (6). However, the sum of friction and base reaction remains equal to the head action (i.e. dead load plus raft reaction), ensuring the static equilibrium of the pile.

Finally, the static equilibrium of the pile shows that mobilised bearing capacities increase with temperature. Trends were evaluated by performing linear regressions along linear parts of the curves between +0 and $+20{ }^{\circ} \mathrm{C}$. These estimates were then compared to those of Amatya et al. [2] based on field measurements. The thermal stress induced at the head was estimated to be $-150 \mathrm{kPa} /{ }^{\circ} \mathrm{C}$ based on the field data, whereas it is equal to $-115 \mathrm{kPa} /{ }^{\circ} \mathrm{C}$ based on the numerical analyses. Induced pile tip compression was estimated to be $-79 \mathrm{kPa} /{ }^{\circ} \mathrm{C}$ from the field data, while the numerical analyses suggest a value of $-62.5 \mathrm{kPa} /{ }^{\circ} \mathrm{C}$.

4.1.1.2 The Lambeth test pile Since the Lambeth test pile qualifies as a floating pile, little base compression is observed. The head action, equal to the pile load plus the head reaction, is mainly transmitted to the soil through shaft friction.

As expected, an increase in the pile temperature leads to greater mobilised shaft friction in the lower part of the pile since it experiences downward displacements.

Conversely, cooling the pile induces a decrease in the mobilised shaft friction along the lower part of the pile while it increases in the upper part of the pile. The small amount of base compression can be lost as the pile tip heaves when the pile is cooled (Fig. 6).

The important discontinuity of shaft friction around a temperature variation equal to zero is mainly due to the

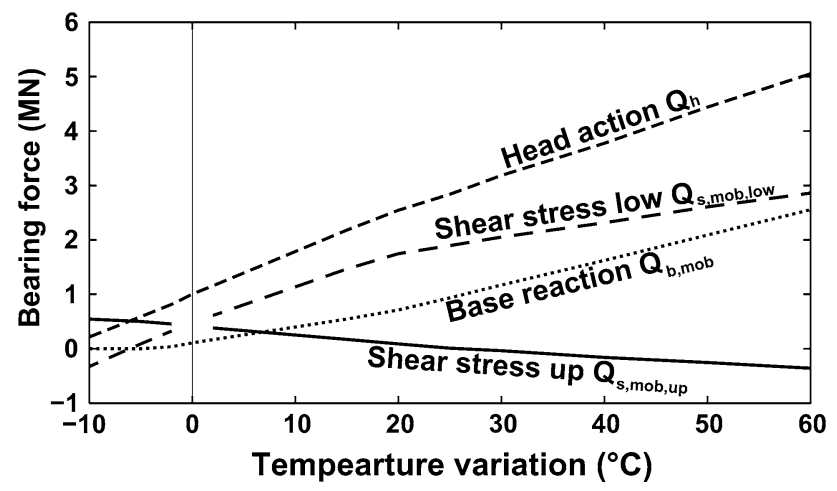

Fig. 5 Evolution of the bearing forces mobilised by the EPFL test pile under monotonic temperature variation difference in head stiffness values used for heating $(10 \mathrm{GPa} / \mathrm{m})$ and cooling $(0.1 \mathrm{GPa} / \mathrm{m})$. However, the total shaft friction plus the base compression remains equal to the head action, ensuring the pile equilibrium.

Finally, the overall mobilised bearing capacity, represented by the head action, increases with temperature and reaches a plateau for a temperature variation of about $+20{ }^{\circ} \mathrm{C}$ as the pile mobilises its ultimate bearing force (Fig. 6).

Values obtained from field data and from the present numerical analyses are in agreement. Trends were estimated along the linear parts during heating (i.e. between +0 and $+20{ }^{\circ} \mathrm{C}$ ). Amatya et al. [2] estimated that there is no thermally induced stress at the Lambeth test pile tip or head while numerical analyses give small values of -4 and $-41.6 \mathrm{kPa} /{ }^{\circ} \mathrm{C}$ for base compression and head action, respectively.

In conclusion, the estimated variations of bearing capacities are in agreement with field data. The EPFL test pile has important margins of safety because it was over-designed, while the Lambeth College test pile mobilises its ultimate bearing force after a temperature increase of $+20{ }^{\circ} \mathrm{C}$.

\subsubsection{Shaft friction mobilisation processes}

4.1.2.1 The EPFL test pile The evolution of the shaft friction along the EPFL test pile is shown in Fig. 7. As described in Sect. 3.3, the variations in shaft friction within a soil layer are greater at the boundary farthest from the null point. Ultimate shaft friction in soil layer B starts being mobilised from the layer base, while layer $\mathrm{C}$ mobilises all its ultimate force for a temperature variation of $+60{ }^{\circ} \mathrm{C}$.

Negative friction develops easily in the upper part of the pile during heating because the mechanical loading, prior to temperature variation, does not induce major friction mobilisation in this area (mainly due to the fact that the pile is over-designed).

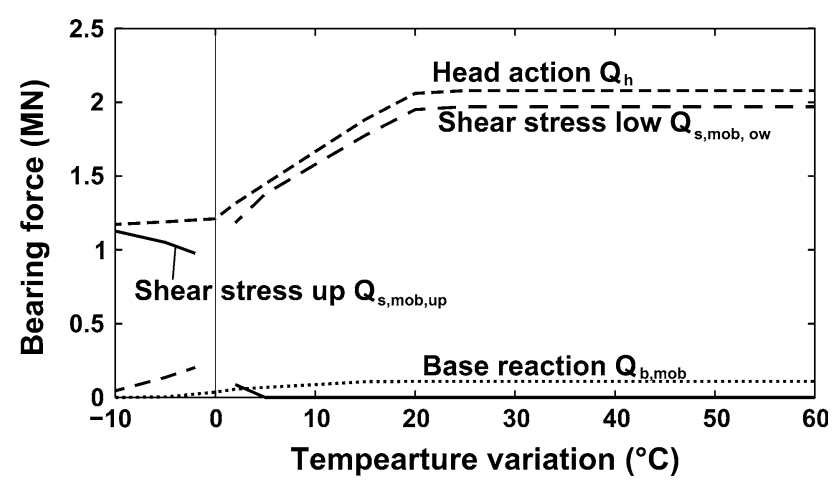

Fig. 6 Evolution of the bearing forces mobilised by the Lambeth test pile under monotonic temperature variation 


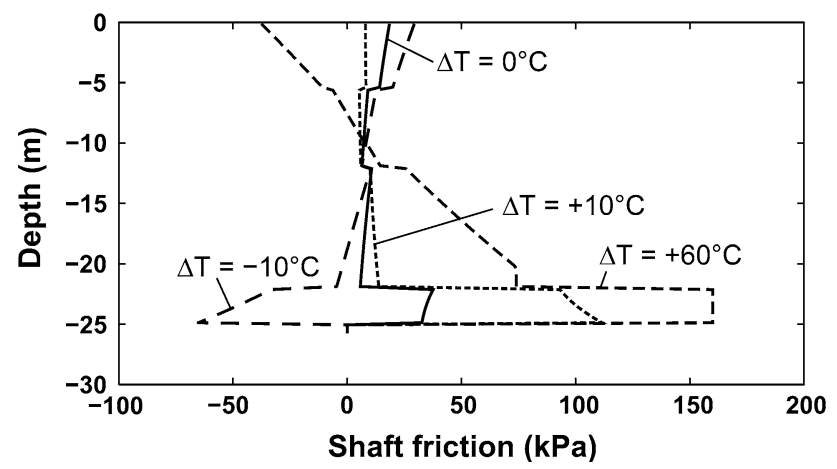

Fig. 7 Evolution of the profile of mobilised shaft friction along the EPFL test pile

This case study highlights the importance of the initial mechanical loading as a starting point for the thermal loading and illustrates the different mechanisms described in Sect. 3.3.

4.1.2.2 The Lambeth College test pile The impact of heating or cooling on the mobilised shaft friction of the Lambeth College test pile shows that floating piles are extremely sensitive to thermal loading.

Shaft friction increases below the null point as the pile is heated. The greatest variations in shaft friction are observed at the lower edges of soil layers (Fig. 8).

Since the design factor of safety for the Lambeth test pile is 1.73, mechanical loading mobilises an important part of the shaft friction prior to thermal loading. As a result, the pile mobilises its ultimate bearing force for a temperature variation of $+20{ }^{\circ} \mathrm{C}$ (Fig. 6).

However, negative friction can also develop while the pile is cooled. Indeed, a lower head stiffness $K_{\mathrm{h}}$ equal to $0.1 \mathrm{GPa} / \mathrm{m}$ was used for the cooling phase, while $10 \mathrm{GPa} /$ $\mathrm{m}$ was used when heating. Therefore, the null point location changes significantly from the top part of the pile to the bottom section of it, leading to the cooling profile observed in Fig. 8, where the ultimate shaft friction is reached in the upper portion of the pile while negative friction develops in the lower part of the pile for a temperature variation of $-10{ }^{\circ} \mathrm{C}$.

\subsection{Representative case studies}

\subsubsection{Evolutions of bearing capacities with temperature}

4.2.1.1 Floating pile The floating pile case study was designed with no base resistance so that it does not appear on Fig. 9 (i.e. it is equal to zero). As expected, the head reaction and shaft friction along the lower part of the pile increase with temperature, while the shaft friction along the upper section of the pile decreases.

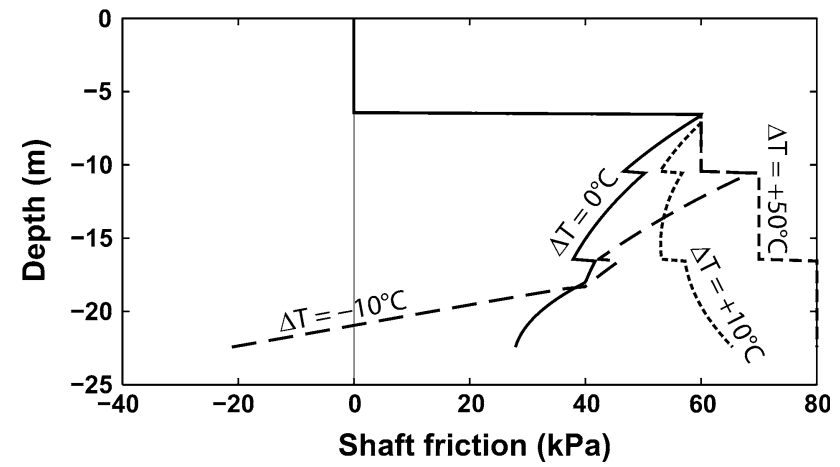

Fig. 8 Evolution of the profile of mobilised shaft friction along the Lambeth test pile

The ultimate bearing capacity of the representative floating pile is never reached for the temperature variations investigated. Indeed, the thermal expansion of the pile induces a reaction at the pile head that is almost equal to the pile mechanical load (i.e. the load on the pile is doubled from 0.6 $\mathrm{MN}$ at $+0{ }^{\circ} \mathrm{C}$ to about $1.2 \mathrm{MN}$ at $+60{ }^{\circ} \mathrm{C}$ ), while the factor of safety of the pile is equal to 2.5 (i.e. the pile can mobilise forces up to 2.5 times its mechanical load).

4.2.1.2 Semi-floating pile The behaviour of the semifloating pile is shown by the non-negligible base compression observed in Fig. 10.

Base compression and shaft friction along the lower part of the pile increase with temperature, while the shaft friction along the upper portion of the pile decreases. The head reaction increases as the pile head heaves with temperature.

In that case, like the floating pile, the head reaction, which represents the real pile load, is almost doubled for a temperature increase of $+60{ }^{\circ} \mathrm{C}$ so that the factor of safety of 2.5 still prevents the ultimate bearing force from being mobilised.

The transition in shaft friction from positive to negative temperature variations is sharper in the semi-floating pile than in the floating pile because of the importance of dissymmetry in the pile confinement.

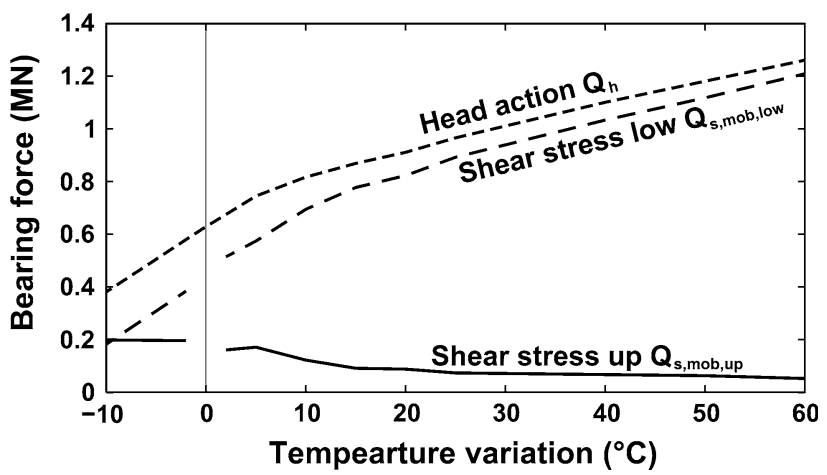

Fig. 9 Evolution of the bearing forces mobilised by the representative floating pile under monotonic temperature variation 
4.2.1.3 End-bearing pile End-bearing piles are characterised by negligible shaft friction. Therefore, the load is transferred to the ground exclusively (from a design standpoint) through pile tip compression. As a result, the base compression equals the head load at any time.

The compression induced by the mechanical load only (i.e. for zero temperature variation) is lower than $0.8 \mathrm{MN}$ so that it remains within the elastic domain of the $t_{\mathrm{b}}-z$ curve (i.e. from 0 to about $8,836 \mathrm{kN}$ ). Therefore, the single slope change observed while heating for a temperature increase of $+10{ }^{\circ} \mathrm{C}$ suggests that:

- for a temperature increase between 0 and $+10{ }^{\circ} \mathrm{C}$, the pile tip compression remains elastic;

- for a temperature increase between +10 and $+60{ }^{\circ} \mathrm{C}$, the pile tip compression is elastoplastic.

Unloading of the pile tip during pile thermal contraction is expected to occur according to the same slope as elastic loading. However, Fig. 11 shows a small slope change when changing from heating to cooling. This effect is attributed to the accuracy of the numerical analyses. Indeed, the determination of the null point depth, which drives the expansion or contraction of the pile, is achieved with an accuracy of $0.2 \mathrm{~m}$ in the present analysis (i.e. the 10 -m-long pile is divided into 50 identical elements).

\subsubsection{Shaft friction mobilisation processes}

4.2.2.1 Floating pile Evolution of the shaft friction profile with temperature is described in Sect. 3.3 and is illustrated for the representative floating pile in Fig. 12. Mobilised shaft friction increases along the upper part of the pile and decreases along the lower part during heating, and vice versa during cooling. The ultimate positive shaft friction starts to be mobilised from the pile tip during heating, and negative friction can develop when cooling because of the relatively weak shaft friction mobilisation under mechanical loading.

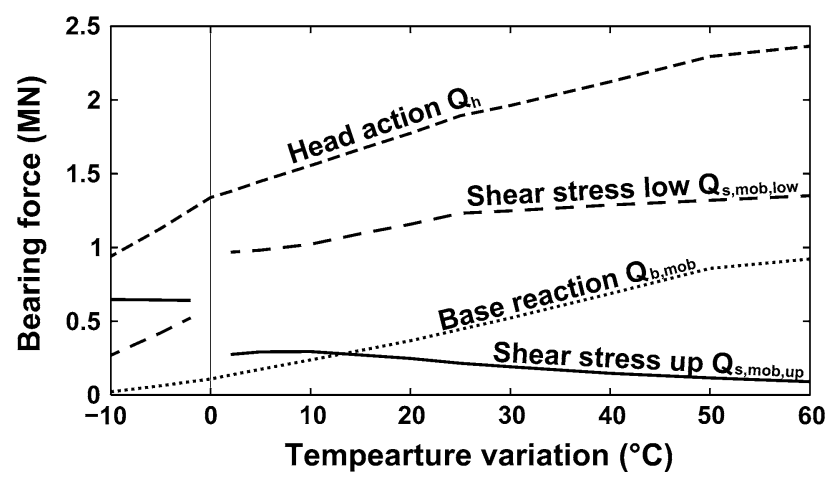

Fig. 10 Evolution of the bearing forces mobilised by the representative semi-floating pile under monotonic temperature variation

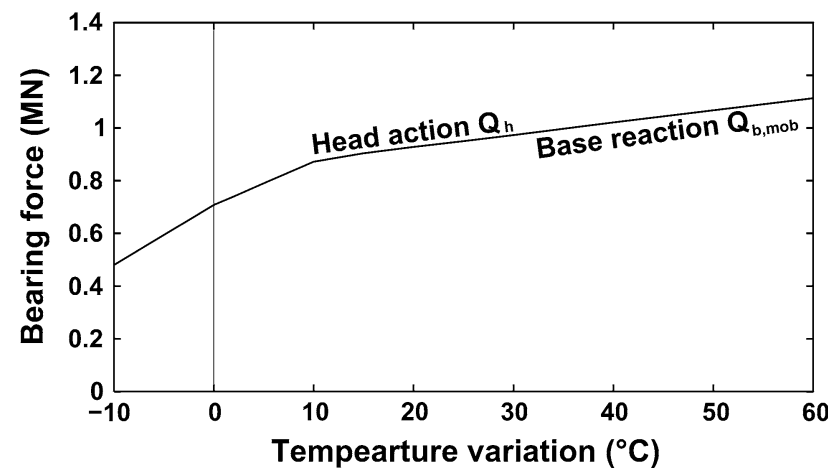

Fig. 11 Evolution of the bearing forces mobilised by the representative end-bearing pile under monotonic temperature variation

4.2.2.2 Semi-floating pile The mechanical load applied to the semi-floating pile is two times greater than the loads applied to the two other representative case studies in order to keep a safety factor of about 2.5. As a result, the shaft friction mobilised under mechanical loading is greater than that observed for the floating pile (Fig. 13). Therefore, ultimate positive shaft friction is mobilised along the entire lower portion of the pile for a temperature increase of $+60{ }^{\circ} \mathrm{C}$, while negative friction develops close to the pile head (Fig. 13).

\section{Non-failing mechanisms and pile serviceability}

\subsection{In situ test piles}

The null point rises when the pile is heated, as shown in Fig. 14. This is explained by the evolution of the different stiffnesses representing the soil (i.e. base compression and shaft friction) and the structure (head action). Indeed, if the pile-structure interaction is represented by a linear spring whose value does not change, the soil is modelled with nonlinear springs whose stiffnesses decrease with the magnitude of the displacement (Sect. 3.1). As a result,

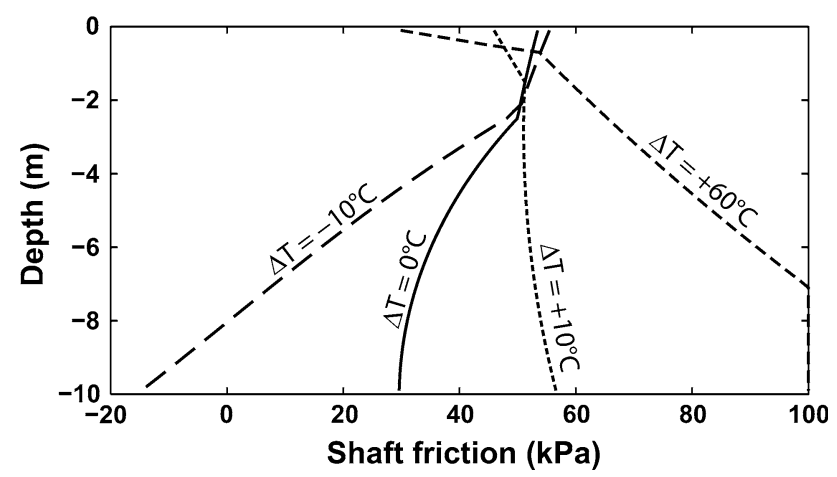

Fig. 12 Evolution of the profile of mobilised shaft friction along the representative floating pile 


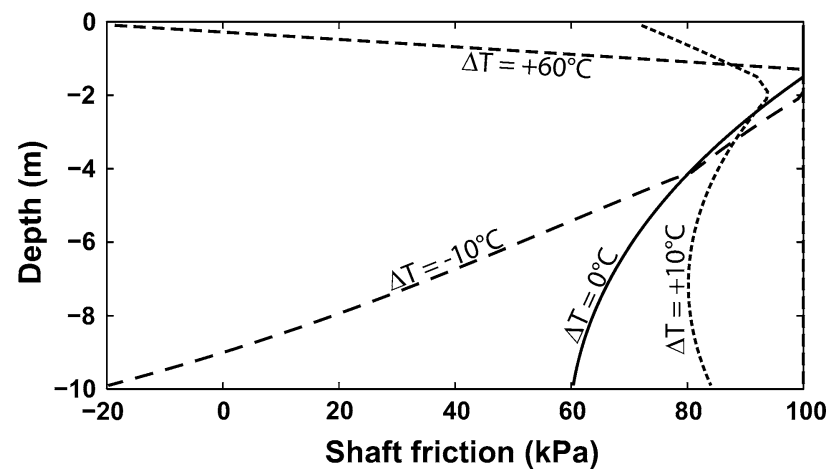

Fig. 13 Evolution of the profile of mobilised shaft friction along the representative semi-floating pile

monotonically expanding the pile induces a reduction in the soil stiffness while the head stiffness remains constant. The soil representative stiffness can attain zero when the ultimate bearing force is mobilised. Therefore, since the apparent stiffness of the soil is reduced, the null point moves towards the pile head in order to maintain the pile equilibrium.

Values of null point depth observed in the analyses are similar to those found when analysing field data. Amatya et al. [2] give null point depths of -6 and $-12.5 \mathrm{~m}$ for temperature variations of +10 and $+18{ }^{\circ} \mathrm{C}$, respectively, while the analyses give depths of -5 and $-12.75 \mathrm{~m}$ for the Lambeth and EPFL test piles.

The serviceability of the two test piles was also investigated, and head displacements are plotted against temperature variations in Fig. 15. The EPFL test pile experiences significant head displacements, whereas the Lambeth College test pile has limited head heave when heating. The important pile head heave observed in the EPFL test pile is mainly attributed to its over-design. Conversely, the EPFL test pile experiences less settlements when cooled than the Lambeth College test pile.

The pile heave limitation observed in the Lambeth College test pile comes from the fact that it reaches its ultimate bearing force. As a result, the null point rises and

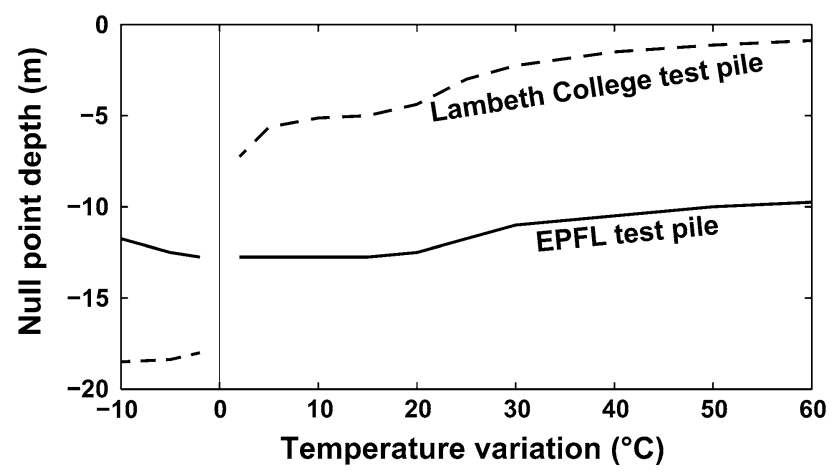

Fig. 14 Evolution of the depth of the null point with temperature variation for the EPFL and Lambeth test piles reaches the pile top which leads to the stabilisation of the pile head heave. In the opposite way, the EPFL test pile experiences an almost linear increase in pile head heave with temperature. This arises from the considerable amount of bearing force that this pile can still mobilise after mechanical loading. The effect of over-sizing the piles is further investigated with the representative case studies in Sect. 5.2.

Finally, no geotechnical failure could be observed even if the Lambeth College test pile mobilised its ultimate bearing force when heating. Indeed, even if the pile mobilises the ultimate friction and base compression, the null point prevents excessive settlements since at least this point remains stable under temperature variations. Furthermore, when bearing capacities reach the ultimate state, the null point reaches the pile head [because this is the only way to mobilise the ultimate shaft friction, see Eq. (6)]. As a result, the pile head does not move any further.

Therefore, it is simply necessary to ensure that pile head heave or settlement induced by thermal expansion or contraction remains within acceptable limits for the structure being supported.

\subsection{Representative case studies}

The pile serviceability was assessed for the three different types of pile whose head movements with temperature are given in Fig. 16. The three representative cases with a factor of safety equal to 2.5 have similar serviceability, and the head displacements do not exceed $0.5 \mathrm{~mm}$ (i.e. 1,000 times less than the pile diameter).

The non-failing mechanisms taking place within geothermal piles during temperature variation (i.e. increase or decrease) were described in the previous sections and it was shown that over-designing a geothermal pile might not be efficient from a serviceability standpoint. Therefore, the representative cases were utilised to further investigate this aspect.

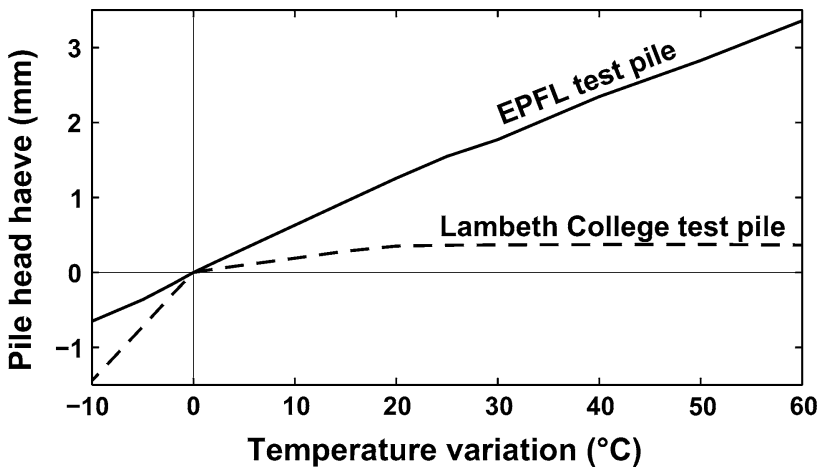

Fig. 15 Thermally induced pile head displacements for the EPFL and Lambeth test piles. Displacements are taken relative to pile settlement after mechanical loading 
Different values for the factor of safety $(2.5,5$ and 10) were adopted for each of the three case studies, and the comparisons are presented in Fig. 16. Modifying the factor of safety is achieved by dividing the mechanical load $P$ applied to the piles (see Table 3 ) by 2 and 4 to obtain factors of safety equal to 5 and 10 , respectively.

Results of the simulations show that over-designing geothermal piles does not have a positive influence from a serviceability standpoint and it can even have a negative impact as serviceability limits are enlarged.

For the three cases investigated, the factor of safety starts having a significant effect for temperature increases greater than $+20{ }^{\circ} \mathrm{C}$ and the end-bearing pile seems to be more sensitive to the factor of safety than the other two scenarios.
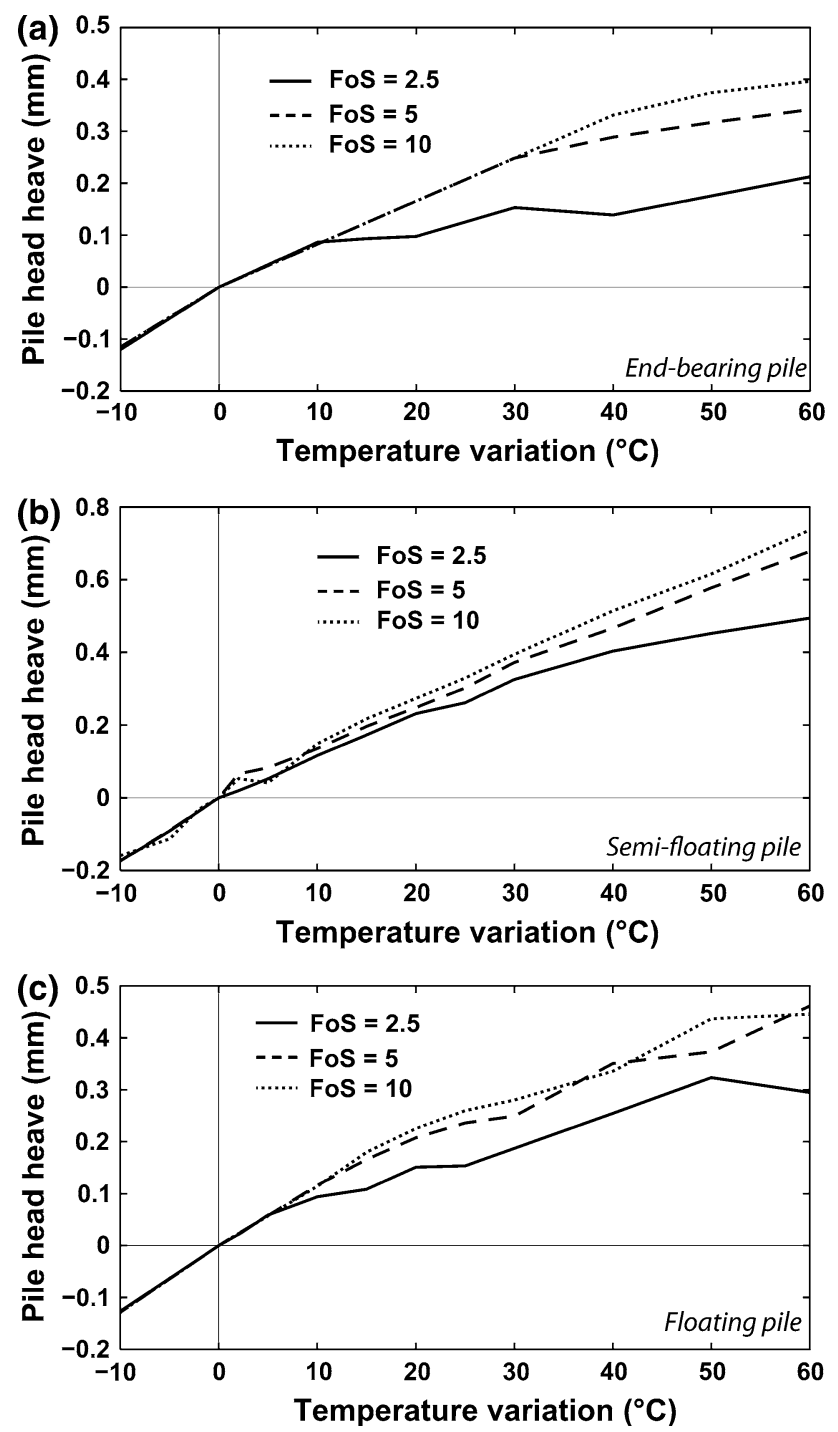

Fig. 16 Pile head displacements with temperature for the a endbearing pile, b semi-floating pile and c floating pile. Pile head displacements are relative to head settlements after mechanical loading
In conclusion, the over-sizing of geothermal piles may not provide better serviceability while it does increase the cost.

\section{Conclusions}

The present study gives some insight into the bearing mechanisms induced by temperature variations in single geothermal piles under monotonic thermal loading.

Dividing the geothermal pile into two parts delimited by the null point allows a better understanding of the evolution of bearing capacities under either heating or cooling.

Indeed, the section of the pile above the null point experiences upward displacements when heated and downward displacements during cooling. Conversely, the pile section below the null point settles during heating and heaves when cooled.

Therefore, heating induces an increase in shaft friction along the lower part of the pile and leads to greater pile tip compression, while it relieves the shaft friction along the upper part of the pile and increases the pile head heave. On the other hand, cooling induces a reduction in shaft friction along the lower part of the pile with a release of the pile tip compression while the shaft friction along the upper portion of the pile is increased and the pile head settles.

It is shown that the pile head heave or settlement induces a reaction from the supported structure that brings load variations to the pile. As a result, the bearing force mobilised by the pile varies with temperature.

Because the pile head heaves during heating, the capping effect of the structure on top of the pile induces an additional (downward) load which must be balanced by the mobilised bearing force. Therefore, the total mobilised bearing force increases when the pile is heated.

Conversely, the pile head settlements observed when cooling induce a pulling (i.e. upward) reaction that relieves a part of the pile mechanical load. As a result, the overall mobilise bearing force of the pile is reduced.

However, if the pile-structure interaction is neglected in order to maximise the pile head movements so that the design remains conservative under monotonic thermal loads, it should not be ignored when cyclic thermal changes are considered. Indeed, the pile-structure stiffness determines the additional load applied to the pile head. Therefore, unloading after a monotonic temperature change will strongly depend on the mobilised bearing force prior to unloading. In this case, neglecting the pile-structure interaction may lead to a non-conservative design as the pile load prior to unloading could be poorly estimated and the accumulated irreversible settlements might be underestimated. However, it is not an easy task to estimate the head stiffness as it may involve the whole of the supported 
structure as well as the position and displacements of the other piles. As a conclusion, this particular aspect needs further investigation in order to estimate whether or not the differences between the two design methods (i.e. with and without head stiffness) are significant.

The mechanisms involved in the variations of the bearing forces mobilised by the piles under temperature variation were not found to induce failure because at least one point of the pile remains stationary (i.e. the null point), preventing excessive pile head settlements for the range of temperature variations investigated.

Finally, it is shown that increasing the factor of safety of geothermal piles does not provide better serviceability, while it can significantly increase costs.

Acknowledgments The authors want to thank Marc Randolph (University of West Australia) and Kenichi Soga (Cambridge University, UK) for the fruitful discussions about this work. Financial support of EOS Holding through the GRETEL II project is much appreciated.

\section{References}

1. Amar S, Clarke BGF, Gambin MP, Orr TLL (1991) The application of pressuremeter test results to foundation design in Europe, Part 1: predrilled pressuremeters - self-boring pressuremeters., European Soil Mechanics and Foundation Engineering, European Regional Technical Committee $N^{\circ}$. 4. A. A. Balkema, Rotterdam, The Netherlands

2. Amatya BL, Soga K, Bourne-Webb PJ, Amis T, Laloui L (2012) Thermo-mechanical behaviour of energy piles. Géotechnique 62(6):503-519
3. Armaleh S, Desai C (1987) Load deformation response of axially loaded piles. J Geotech Eng 113(12):1483-1500

4. Bourne-Webb PJ, Amatya B, Soga K, Amis T, Davidson C, Payne P (2009) Energy pile test at Lambeth College, London: geotechnical and thermodynamic aspects of pile response to heat cycles. Geotechnique 59(3):237-248

5. Choi JH, Chen RHL (2005) Design of continuously reinforced concrete pavements using glass fiber reinforced polymer rebars., Publication No. FHWA-HRT-05-081. Washington, D.C

6. Coyle HM, Reese LC (1966) Load transfer for axially loaded piles in clay. J Soil Mech Found Div 92(2):1-26

7. Frank R, Kalteziotis N, Bustamante M, Christoulas S, Zervogiannia $H$ (1991) Evaluation of performance of two piles using pressuremeter method. J Geotech Eng 117(5):695-713

8. Frank R, Zhao SR (1982) Estimation par les paramètres pressiométriques de l'enfoncement sous charge axiale de pieux forés dans des sols fins. Bull Liaison Lab Ponts Chaussées 119:17-24

9. Knellwolf C, Péron H, Laloui L (2011) Geotechnical analysis of heat exchanger piles. J Geotech Geoenviron Eng 137(10): 890-902

10. Laloui L, Di Donna A (2011) Understanding the behaviour of energy geo-structures. Proc ICE Civil Eng 164(4):184-191

11. Laloui L, Moreni M, Vulliet L (2003) Comportement d'un pieu bi-fonction, fondation et échangeur de chaleur. Can Geotech Journal 40(2):388-402

12. Laloui L, Nuth M, Vulliet L (2006) Experimental and numerical investigations of the behaviour of a heat exchanger pile. Int $\mathrm{J}$ Numer Anal Method Geomech 30(8):763-781

13. Randolph MF, Wroth CP (1978) Analysis of deformation of vertically loaded piles. J Geotech Eng Div 104(GT12):1465-1488

14. Seed HB, Reese LC (1957) The action of soft clay along friction piles. Trans Am Soc Civil Eng 122:731-754

15. Stewart MA, McCartney JS (2012) Strain distributions in centrifuge model energy foundations. ASCE GeoCongress 2012. Oakland, CA 